\title{
When death approaches: reverting or exploiting emergent inequity in a complex land-use table-board game
}

\author{
Luís García-Barrios $^{1}$, Raúl García-Barrios $^{2}$, Juana Cruz-Morales $^{3}$ and James A. Smith $^{1}$
}

\begin{abstract}
The lives of poor landowners in tropical mountains depend upon their collective capacity to create and coordinate social preferences derived from their interacting communalistic, hierarchical, and reciprocal exchanges. External actors currently contend for these territories under market rules that are modifying such preferences. We present the design, experimental implementation, and analysis of results of a four-player, land-use board game with stark resource and livelihood limits and coordination/cooperation challenges, as played (separately) by 116 farmers and 108 academics, mainly in the tropical mountains of Chiapas, Mexico. In game session one, we trained and framed players in moral economy, a human core feeling and communalistic norm of solidarity and mutual obligation, which translates into "all players must survive." In session two, we explored to what extent moral economy resisted as a social preference under a hypothetical external monetary incentive scheme unfavorable to it. Using an approach that combines spot game analysis and experimental work, we studied the social preferences that emerged during session two among advantaged and disadvantaged players to deal with inequity in land appropriation and use when imminent "death" approaches. We make comparisons between farmers and academics. Players evolved moral economy, competitive domination, i.e., let competition decide, and coalition, i.e., advantaged players ask the dying to surrender land and die prematurely in exchange for a share of the dismal profits. Farmers basically stuck to the first two preferences in similar proportions whereas academics clearly shifted to coalition, a last-resort choice, which allowed disadvantaged players some final leverage and advantaged players use of liberated resources to improve efficiency. Coalition as strategic cooperation among the unequal is part of the culture in which academics are being educated as sustainability professionals and toward which farmers are being steered. In the stringent social-environmental conditions of this game, the results were a Pareto-superior form of equity, albeit with land surrendering, and many more deaths than other preferences.
\end{abstract}

Key Words: inequity; Mexico; payments for ecosystem services; role-playing games; rural land use, social-ecological experiments; social preferences; tropical mountains

\section{INTRODUCTION}

The lives and assets of many poor landowners in fragile, highly populated tropical mountains at the forest frontier depend to a significant extent on their collective capacity to create and coordinate social preferences. These are derived from the tension between different context-dependent behavioral propensities of the individual, associated with coexisting communalistic, hierarchical, and reciprocity exchanges (Fiske and Haslam 2005, Graeber 2011, DeScioli and Krishna 2013). These preferences can affect social and ecological resilience by: (1) regulating land/ resource property and distributional rights; (2) coordinating the use of land and other resources in ways that are suitable for these fragile environments; (3) reducing vulnerabilities and conflicts derived from or enhanced by emergent inequity among local people; and (4) maintaining or developing the necessary social cohesion to negotiate interaction terms with other social actors who support or threaten their livelihoods.

In the last 30 years, an increasing number of external actors contend for tropical mountain territories under new marketoriented economic norms and rules (Cruz-Morales 2014, Speelman et al. 2014a). Some are mainly interested in appropriation and enrichment, others in sustainable management, and still others in poverty alleviation or social development. New development instruments with strong but contrasting, or even rival, incentive/moral contents have emerged and now coexist in these spaces: (1) huge private land buying or occupation contracts; (2) public and private incentives to both degrading and nondegrading forms of agriculture and animal husbandry; (3) private and governmental exclusion and regulation of biodiversity hotspots; (4) individualized monetary payments to promote market provision and compensate for price deregulation of crops and livestock, i.e., market provision subsidies; and (5) collective and individualized monetary and nonmonetary payments for ecosystem service stewardship (PES).

Such instruments have altered the set of incentives and norms influencing land-allocation decisions in rural areas (Liverman and Vilas 2006). Market provision subsidies have been related to modest increases in welfare, more deforestation, and bias in benefit of big landowners, and indirectly to land concentration (Klepeis and Vance 2003, Schmook and Vance 2009, Cortina 2014). Payments for ecosystem service are a matter of intense debate regarding their nature, i.e., whether a market or an induction transaction (Hiedanpää and Bromely 2014), their long term effectiveness and efficiency (Wunder 2006, Pascual et al. 2014), their crowding out intrinsic motivations for conservation (Pascual et al. 2014), their interaction with local conservation and social norms (Villamor and van Noordwijk 2011), their negative impacts on equity at the global level, i.e., unfair relations between providers and consumers, with a bias in favor of selected regions and big landowners, and at the local level, i.e., elite capturing, rent seeking, and land concentration (Corbera and Pascual 2012, Pascual et al. 2014).

Such effects resonate with the complexity of results derived from game theoretical analysis (Fehr and Gächter 2002a), lab and field experiments (Fehr and Gächter 2002b, Bowles 2008, Anderies et al. 2011, Janssen et al. 2011), psychological experiments (DeScioli and Krishna 2013) and role playing games (Narloch et al. 2012) 
that explore how the interplay of sanctions and incentives, both material and nonmaterial, affect social preferences and behaviors in different socio-environmental contexts.

Role-playing games are being used as experimental tools to study the behavior of multiple actors involved in conflict and negotiation over territories, livelihoods, resources, ecosystem services (e.g., Étienne 2003, Sandker et al. 2010), and as participatory social education tools to facilitate communication and reflection among these actors to build a common ground for effective governance (Barreteau 2003, Étienne 2014). Few roleplaying games have been developed to explicitly explore the interplay of recent external payments and incentive schemes that induce potentially conflicting social preferences and uses of land in the tropics (e.g., Villamor and van Noordwijk 2011, Narloch et al. 2012, Speelman et al. 2014b) and, further, to allow for comparative analysis of actors expected to combine differently the basic economic principles in building social preferences and behaviors and of their comparative response to such economic instruments.

In 2011, we developed and tested a two-session game, built on the Sierra Spring platform developed by García-Barrios et al. (2011), in which draconian features amplify some of the issues of locally inducing land appropriation and use through individualized cash transfers to farmers. In session one, the game is designed so that players representing rural households coordinate their decisions over land use and appropriation, to secure that all achieve a minimum household income needed to stay alive (a form of moral economy; Scott 1977), and that environmental thresholds, vital for their survival, are not crossed. In session two, sustaining moral economy stands at odds with the opportunity advantaged players have of individually profiting from the cost/benefit schemes of land-use-induction payments, i.e., reciprocity/hierarchical exchanges, offered by external actors. Disadvantaged players face imminent "death" in a time horizon but retain the capacity to pull advantaged players into the tomb, to punish inequity, by collapsing the environment. While test-driving the game with graduate students we found that, in session two, interesting strategies emerged to face the contradictions and deal with the inequities involved. A spot-game analysis of the strategic combinations revealed a structure of equilibria that allow interpretation of the emerging social preferences of the players.

The capacity of tropical mountain dwellers to escape or submerge into inequity, poverty traps, and physical or social death in the very challenging conditions of neoliberalism (Chappell et al. 2013) depends to some extent on how they understand the nature of new opportunities and risks, and reshape, for better or worse, their social preferences and interactions. Games cannot fully capture the socio-political and environmental nuances of real-life interactions between the actors involved in such a process. They may however help farmers to become aware, in a safe and engaging form, of how they might be playing out their communalistic, hierarchical, and reciprocity exchanges, and building social preferences when confronted with current environmental and social threats and opportunities. Academics that influence policy making and/or promote and operate monetary cash transfer programs need to better understand the actors and issues involved as well (Pascual et al. 2014); thus, they might benefit from becoming aware of their own reactions to the game, and how these differ from those of farmers. Because impacts of games seem to matter, it's important to explore in more detail what games can reveal in a stylized, general form to these actors about the abovementioned issues.

We present the features, experimental implementation, and analysis of results of this stylized but complex four-player, landuse board game, as played (separately) in 12 workshops with 116 farmers and 108 academics, mainly in the tropical mountains of Chiapas, Mexico. The experiments conducted in this framework investigate a transition away from moral economy and toward market-based incentives. Specifically, we capture the persistence or collapse of moral economy as a social preference under this transition by means of a hypothetical monetary incentive scheme, which is unfavorable to it and further favors asymmetry in resources and decision power. In simple terms, our key experimental questions are as follows: (1) What happens to moral economy under a shift to market mechanisms that render it no longer obligatory? (2) What other social preferences evolve under this transition? (3) How do different actors, i.e., farmers and academics, play differently? For this purpose, we study the evolution of qualitatively different social preferences that emerge during the second session of the game, both empirically and theoretically, we compare such processes between tropical mountain smallholders and academics interested in socioenvironmental issues, and we discuss the possible reasons and implications.

\section{THE GAME}

Our game experiment consisted of two time-restricted, 50 minute, sessions. Both sessions share a set of fixed rules, established by the game board's structure and environmentally binding conditions, but differ in some other additional rules. The purpose of the first session is to train the players on the mechanics of the game and provide some cognitive and emotional framing. The second session is the core experiment; therefore we focus mainly on its results.

\section{Fixed rules of the Sierra Springs platform}

The Sierra Springs game board (Fig. 1) represents a locale of 48 initially pristine forest sites, e.g., single-hectare plots, each covered by a small, green pristine forest token, divided into four quadrants. At the center of the board, a buoyant spring flows into four creeks, which form the borders between quadrants. There are four players, each of whom is assigned a quadrant and given a set of tokens, which represent different land uses with corresponding point values: $6 \mathrm{~F}$ tokens, representing managed forest, are worth one point each; $6 \mathrm{M}$ tokens, moderate cattle grazing, worth two points each; and 6 I tokens, intensive cattle grazing, worth three points each.

Development with an F tokens does not deforest a site, so its pristine forest token remains on the board. $\mathrm{M}$ and I tokens do deforest, and the pristine forest tokens are removed and placed on a card, referred to as the deforestation table, which is provided so that players may keep track of the extent of deforestation in the locale. The card is shared by all players and has a limit of 32 sites.

Each player seeks to make a living by developing sites, i.e., placing tokens upon them. The eight sites in the interior of a quadrant are available only to its owner. Those within a quadrant border, 
i.e., a riparian border, are available to either of the neighbors that it separates. A player will own those riparian sites if she colonizes them before her neighbors, i.e., first come, first served.

Fig. 1. The Sierra Spring table board and token display near the end of a session 1 game. Each player has a quadrant and distinct token color. Sites on creeks bordering quadrants are owned based on a first come first served rule. Land-use values are: $\mathrm{F}$ (managed forest $)=1 ; \mathrm{M}$ (moderate grazing $)=2 ; \mathrm{I}$ (intensive grazing) $=3$. Token deployment is reversible at any time. The fixed rules allow all players to survive by making at least 24 points each without breaching the 4 environmental limits and land-use restrictions. There are thousands of solutions, but finding one is nontrivial for most people. In this image, 31 sites have been deforested out of the maximum allowable 32. Players 1, 2, and 3 have achieved 24 points but player 4 is still lacking a point and the quadrant 3/quadrant 4 border is breaching the rule: no more than 2 deforestations on a creek. If player 3 fixes the creek by changing his $\mathrm{M}$ token to an $F$ token, he too will be lacking a point; if player 4 does, he will be in an even worse situation. Who will yield? What needs to be rearranged among all or some players so they can all survive?

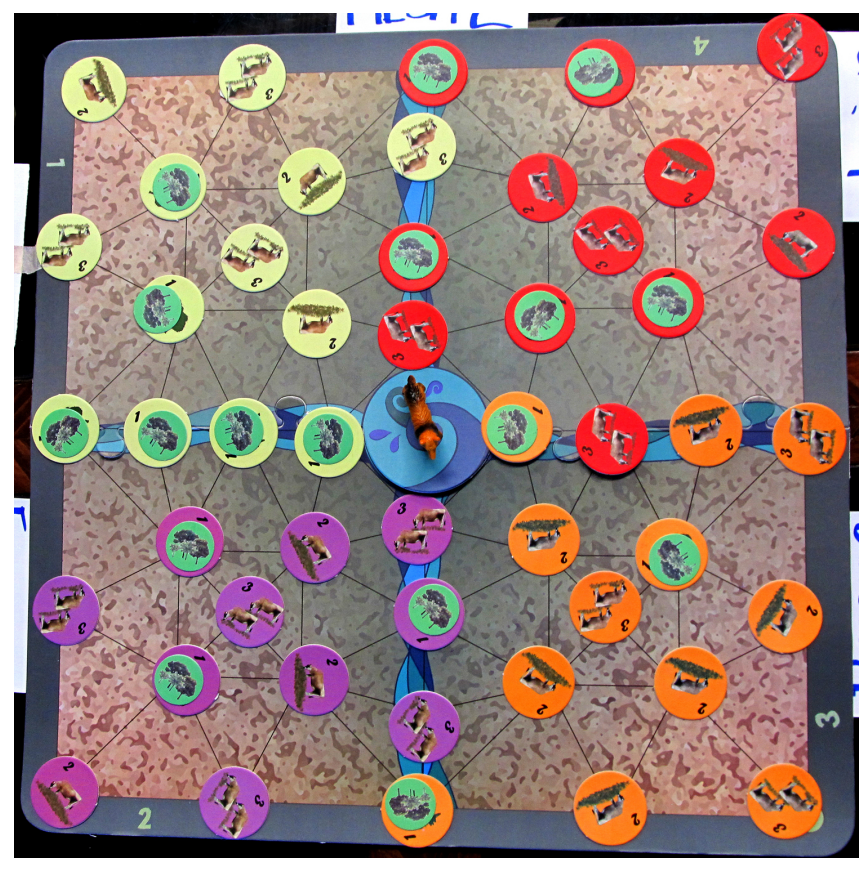

Land use is subject to environmental constraints, which may be expressed by stylized propositions such as "if the spring dries, all players die" or "overgrazing must be avoided because it degrades soil and water to a point that production collapses." Such constraints are captured by 4 rules, which must be followed at any moment in the game: (1) No more than two M or I tokens can immediately surround the spring, otherwise it dries; (2) No more than 32 total deforestations on the board, otherwise the spring dries; (3) No contiguous I tokens, meaning I tokens on sites joined by a line segment within the locale, or its border and creeks (Fig. 1); and (4) No more than $2 \mathrm{M}$ or I tokens on any creek.

Players do not take turns to develop land; instead, each places tokens in the interior and riparian borders of their quadrant at their own will and pace. Any decision made by a player to set a token on the board is reversible at any time during a game. Reversibility seemingly provides players great survival advantages, but remember there is a 50-minute deadline to solve the challenges posed by the game. The players listen to a detailed explanation of Sierra Spring's fixed rules and try them out step by step on the board.

\section{Session 1: training and framing}

Session 1 (S1) adds three rules to the fixed rules. Within the 50minute time limit: (1) all 4 players must earn at least 24 points, i.e., they must stick to a moral economy (ME); (2) at least 2 players must deploy their $6 \mathrm{~F}$ tokens on the board (SixF); (3) if either of these rules is violated, given the board layout at the end of 50-minutes, each player must pay a fine of US\$1.5.

Each team of participants plays one session under the above rules; they are allowed to talk freely to find a collective solution, but only to their team members. The rules are presented to the players in the form of a fictional, but plausible, narrative, which deliberately frames the players by establishing a stylized context for the game (see Appendix 1). Note that the goals of the game (ME and SixF) are framed as enforceable obligations. The stated purpose of $\mathrm{S} 1$ is to allow players to become familiar with the rules and mechanics of Sierra Springs, but an unstated purpose is to allow them to discover, either directly or by reference from other teams, that achieving ME plus SixF is possible. In finding one of the many ways of meeting these goals, participants must engage in a cognitively and emotionally charged competitive, cooperative, and coordinated process.

\section{Session 2: core experiment}

After a 20-minute rest, a second session (S2) with modified rules is announced. Players return to the same positions that they occupied during S1. In preparation for S2, the initial, forested condition of the board is re-established and then the time limit is reset to 50 minutes. Session 2 rules now involve entry costs and prizes to induce land uses. Both will be expressed hereafter in terms of positive or negative bonuses, where 1 bonus equals US\$1.5. The modified rules are:

1. There is an entry cost of 2 bonuses for each player, which is rationalized as a transaction cost of establishing relations with external actors offering land-use bonuses. The external actors are embodied by the game coordinator;

2. If a player does not reach 24 points, they die and pay a fee of 1 bonus;

3. Each survivor deploying six F tokens will receive 1 bonus in payment for hydrological services;

4. Each survivor will receive 1 bonus for each point earned in excess of 24, in payment for market provision;

5. Those who meet the requirements for both (3) and (4) will receive both payments.

Note that ME and SixF goals are no longer framed as obligations. The ME goal can surely emerge as the result of social choices, but this is not mentioned explicitly. Once again a sense of expected net loss is constructed, but this time through an entry cost. Again, S2 rules are framed in the form of a fictional, but plausible, narrative (see Appendix 1). 


\section{EMERGENCE AND STABILITY OF SOCIAL PREFERENCES}

Several months ahead of conducting the experiment, we did some test-driving of S1 and S2 with 32 graduate students in an international workshop on rural sustainability. These students were not included in the final experimental sample. As a result, we could distinguish four social preferences emerging in the game; three were expected but the last was unforeseen. We called them moral economy, competitive domination, revengeful collapse, and coalition with the dying.

We first characterize the social preferences and describe in very general terms their potential payoffs in the Sierra Spring platform. Then we analyze how the interaction among the strategies, which advantaged and disadvantaged players display toward the end of the game, i.e., when death approaches, could evolve toward these four social preferences. However, this is a very difficult task, because it involves understanding the players' complete strategic sets, the expected payoffs resulting from their strategic combinations, the structure of the equilibria that emerge from these combinations, and the stability and efficiency of the different equilibria according to this structure. Although the Sierra Spring platform is a large simplification of reality, it was designed to allow for very complex psychological, cognitive, and behavioral phenomena, thus it allows for many and very complex strategies and equilibria to emerge. We therefore need a more tractable method to further our investigation and understand how the social preferences could emerge as strategy equilibria of the game. This was done through what we will call spot-game analysis. We define a spot game of a larger game as a much simpler game that inherits, or models, interesting aspects of the information, strategical and payoff structures of the larger game, in general or at a particular moment in the game, making the latter's properties much easier to understand, study, and explain. Clearly, a spot game may also be a very good heuristic instrument to uncover interesting hypotheses on the phenomena emerging from the larger game. We used this approach to build the "Little Watershed Game" introduced in a previous paper, as a way to describe the overall properties of Sierra Spring games (García-Barrios et. al. 2011). For readers unfamiliar with game theory and/or some of the terms used, we refer them to Spaniel (2011) or Tadelis (2013) as starting points. An interesting introduction to the evolutionary perspective of game theory can be found in Gintis (2000).

\section{Social preferences and their potential payoffs in the Sierra Spring platform}

Moral economy: all players survive, with or without achieving bonuses. Recall that $\mathrm{S} 1$ was intended to show players that the moral economy goal was nontrivial but attainable. Sticking to it in $\mathrm{S} 2$ is not incompatible with achieving bonuses, as shown in the game configuration of Figure 2.a, but is much more challenging and potentially costly. J. A. Smith and L. García-Barrios (unpublished manuscript) have listed the full set of board-game configurations that meet the moral economy goal under S1 and S2 additional rules (see appendix 2 for a synthesis of methods; this outcome set database is available from authors upon request). There are 2012 ways in which players can attain the moral economy goal in S1, and by eliminating the SixF obligation, S2 expands this number to 18747 . Unfortunately, this greater latitude is offset because in S2 moral economy usually has a net monetary cost for most players. Recall that the team pays up front an entry cost equivalent to 2 bonuses per player, i.e., 8 per team. In a thought experiment performed upon our outcome set database, we have calculated how many bonuses the 18747 possible games would produce for its 74988 imaginary players. Of the players, $68 \%$ would make no bonuses; $28 \%$ would make one; only $3.5 \%$ would make two and break even after discounting the 2 bonus entry cost; only $0.3 \%$ would make three and obtain a modest one bonus profit. Even if both ME and a strict egalitarian sharing of monetary costs and benefits were pursued, a maximum of four bonuses per team is possible (Fig. 2.a), still producing a net cost of one bonus per player. Also, the frequency of such result in the outcome set is only $1.4 \%$, so it is very hard to collectively discover the configurations that will render it. In short, this social preference implies, for most or all players in a team, a disposition to incur a monetary cost to preserve a human core feeling and communalistic norm of solidarity and mutual obligation.

Fig. 2. Schematic diagrams of the Sierra Springs game board showing results that give the maximum possible number of bonuses for the group of four players in S2, under two different conditions: (a) players stick to the moral economy goal, and (b) players abandon it. Colored lines drawn around each quadrant enclose the tokens placed by each player. In (b), players 1 and 3 have been ceded control of all the riparian sites that are available to them. RT = the set of tokens that the player has placed on riparian sites (format is number of $\mathrm{F}$ tokens, number of Ms, number of Is). CT = the complete set of tokens that the player has used (format is the same as for RT). Total bonuses = sum of PES and PB. PES = environmental (hydrological) service bonus and $\mathrm{PB}=$ provision bonus, equal to the number of points earned in excess of the 24 needed for survival.

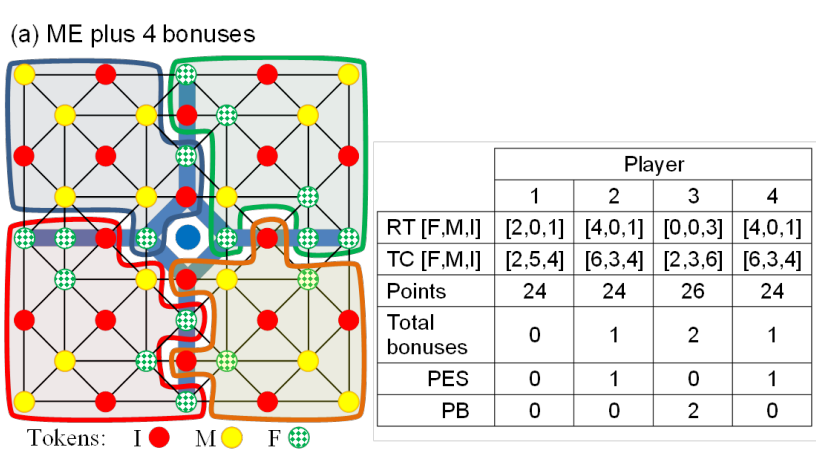

(b) Maximum possible bonuses if ME not met

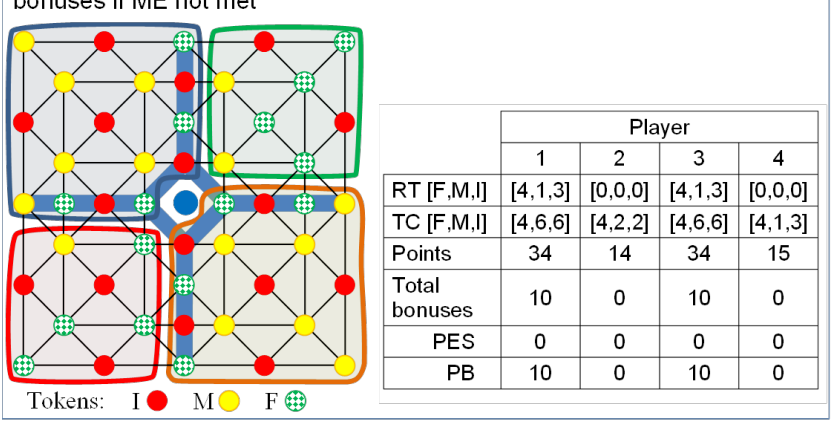


Competitive domination: one or more players are keen to compensate their costs or make a handsome profit and accept the death of the other players as an unavoidable consequence of competition. The outcome set of the game explodes; we have not counted and described it but have found the maximum payoff configuration, which allows 2 players to earn up to 10 bonuses apiece, i.e., an 8 bonus net benefit (Fig. 2.b), but the other 2 will fall short of 24 points and die with a net monetary net benefit of -3 bonuses. To attain near maximum bonuses, the advantaged player's skill and playing speed must be much greater than those of other players, so that they can deforest sites, gain control of the riparian borders quickly, and locate their I tokens optimally. However, differences in performance and competitive will are rarely this asymmetrical within teams, thus higher profits are increasingly difficult to achieve. This social preference implies that advantaged players consider legitimate any outcome of competition, and that disadvantaged players facing imminent death do not resort to revengeful collapse.

Revengeful collapse: disadvantaged players facing imminent death interpret their situation as a violation of equity norms and overflow the deforestation card or deforest the spring, thus killing the game in retaliation. Every player incurs a net benefit of -3 bonuses.

Coalition with the dying: one or more advantaged players, at some point in the game, most probably in the later half, invite the disadvantaged into a deadly coalition, in which the latter die and cede all or part of their riparian sites in exchange for a share in the dismal bonuses that will result. We have therefore a somewhat macabre win-win situation. The maximum-payoff board configuration is the same as in competitive domination (Fig. 2. b). It is still cognitively difficult to discover but not socially difficult to implement because of the agreement among players. If costs, -10 bonuses, and benefits, 20 bonuses, are shared equally, it renders 2.5 bonus per player.

\section{Two-spot dismal games}

Why did these social preferences emerge? Are they solely the result of the perhaps negotiated aggregation of the individual preferences of the players, or does the structure of the game in which they are involved have some influence? We construct some hypotheses by analyzing the properties of two different spot games of S2, which we call "the dismal game," version 1 and version 2. Figures 3 and 4 show the normal form. Both assume that there are two utility maximizing players in a principal-agent relationship, i.e., an asymmetrical relation in which only one player, the principal, has the power to offer different contractual agreements to the other player, the agent, so that the reaction of the latter to each agreement is predictable and the principal may choose the contract that will maximize his own utility.

Suppose inequity among players has emerged during the game, so that the principal is an advantaged player (AP), which has built a competitive advantage in terms of expected payoffs over a disadvantaged player (DP) who is near death, and assume that AP has three pure strategies:

1. Strategy (R): either revert emergent inequity, renounce some or all bonuses, and secure both the spring and moral economy;

2. Strategy (C): continue to compete; and
3. Strategy (Coop): invite the disadvantaged player (DP) to comply with a scheme in which DP dies, releases land that AP will use to obtain more payments, and receives a negotiated share of the dismal monetary income.

Fig. 3. Normal form of the dismal game version 1. Maximum payoffs theoretically attainable by the principal and associated agent payoffs. Colored pairs (agent, principal) are Nash equilibria. The four pairs enclosed in a small square are an example of one of the chicken games embedded in version 1.

\begin{tabular}{|c|c|c|c|c|}
\hline \multirow{6}{*}{ 卢 } & & \multicolumn{3}{|c|}{ PRINCIPAL } \\
\hline & & $\begin{array}{c}\mathrm{R} \text { (revert to no } \\
\text { deaths) }\end{array}$ & $\begin{array}{l}\mathrm{C} \text { (continue to } \\
\text { compete) }\end{array}$ & $\begin{array}{c}\text { Coop (negotiate } \\
\text { and share) }\end{array}$ \\
\hline & Closed lenient (survive) & $(-2,1)$ & $(-3,8)$ & $(-3,1)$ \\
\hline & $\begin{array}{c}\text { Closed severe (if } R \text {, } \\
\text { survive; if not } R \text {, then } \\
\text { punish) }\end{array}$ & $(-2,1)$ & $(-3,-3)$ & $(-3,-3)$ \\
\hline & $\begin{array}{c}\text { Open lenient (if not } \\
\text { Coop, survive; if Coop, } \\
\text { then Coop) }\end{array}$ & $(-2,1)$ & $(-3,8)$ & $(-2,5) \ldots(2.5,2.5)$ \\
\hline & $\begin{array}{c}\text { Open severe (if } \mathrm{R} \text {, } \\
\text { survive; if C, punish; if } \\
\text { Coop, and share } \\
\text { accepted, then Coop; if } \\
\text { not, then punish) }\end{array}$ & $(-2,1)$ & $(-3,-3)$ & $(-3,-3) \ldots(2.5,2.5)$ \\
\hline
\end{tabular}

Fig. 4. Normal form of the dismal game version 2. Payoffs as in version 1, except that those attainable by the principal in cases $\mathrm{C}$, closed lenient, and in cases, $\mathrm{C}$, open lenient, are no longer the maximum, but constrained for different reasons to values lower than 2.5. This allows strategic combinations, i.e., Coop, open lenient, and Coop, open severe, to Pareto dominate over all other Nash equilibria. Colored pairs (agent, principal) are Nash equilibria; blue pairs are also Pareto dominant.

\begin{tabular}{|c|c|c|c|c|}
\hline & \multicolumn{3}{|c|}{ PRINCIPAL } \\
\cline { 3 - 5 } & $\begin{array}{c}\mathrm{R} \text { (revert to no } \\
\text { deaths) }\end{array}$ & $\begin{array}{c}\mathrm{C} \text { (continue to } \\
\text { compete) }\end{array}$ & $\begin{array}{c}\text { Coop (negotiate } \\
\text { and share) }\end{array}$ \\
\cline { 2 - 5 } & $\begin{array}{c}\text { Closed lenient (survive) } \\
(-2,1)\end{array}$ & $(-3,<2.5)$ & $(-3,1)$ \\
\cline { 2 - 5 } & $\begin{array}{c}\text { Closed severe (if } R, \\
\text { survive; if not } R, \text { then } \\
\text { punish) }\end{array}$ & $(-2,1)$ & $(-3,-3)$ & $(-3,-3)$ \\
\cline { 2 - 5 } & $\begin{array}{c}\text { Open lenient (if not } \\
\text { Coop, survive; if Coop, } \\
\text { then Coop) }\end{array}$ & $(-2,1)$ & $(-3,<2.5)$ & $(-2,5) \ldots(2.5,2.5)$ \\
\cline { 2 - 5 } & $\begin{array}{c}\text { Open severe (if } R, \\
\text { survive; if C, punish; if } \\
\text { Coop, and share } \\
\text { accepted, then Coop; if } \\
\text { not, then punish) }\end{array}$ & $(-2,1)$ & $(-3,-3)$ & $(-3,-3) \ldots(2.5,2.5)$ \\
\hline
\end{tabular}

Notice that strategy Coop may be considered as an invitation to negotiate that shortcut's other choices, as it exploits emergent inequity to improve the expected fate of the disadvantaged, but which involves their capitulation and premature death.

Now suppose DP, the agent in disadvantage, may be open or closed to coalition, and lenient or severe about punishing inequity, so that they may respond only with the following actions: 
- Action (S): continue, no matter what, striving for survival until the end of the game;

- Action (P): threat to use the residual power to cross environmental thresholds and pull all players into the tomb to punish growing inequity;

- Action (D): accept AP proposal of negotiated capitulation and premature death.

Thus, the agent (DP) has four strategic responses:

- Closed lenient: If principal: $\mathrm{R}$ or $\mathrm{C}$ or Coop then $\mathrm{S}$;

- Closed severe: If principal: R then S; if principal: C or Coop then P;

- Open lenient: If principal: $\mathrm{R}$ then $\mathrm{S}$; if principal: $\mathrm{C}$ then $\mathrm{S}$; if principal: Coop then D;

- Open severe: If principal: $\mathrm{R}$ then $\mathrm{S}$; if principal: $\mathrm{C}$ then $\mathrm{P}$; if AP: Coop then, if share accepted then D, otherwise P.

The differences between version 1 and version 2 are not difficult to grasp. Notice that the payoffs of version 1 were parameterized using the maximum income the principal (AP) can expect from different social preferences in the Sierra Spring platform. Thus, it represents the whole range of competitive income opportunities provided by $\mathrm{S} 2$. Version 2 intends to model a situation in which the principal has difficulty discovering or using the full range of competitive income opportunities provided by $\mathrm{S} 2$. These difficulties may be cognitive, cultural, educational, or emotional. Thus, we maintain most parameters but assume that the payoffs, which the principal may expect from adopting a competitive strategy, diminish drastically and change the structure of the game qualitatively.

Dismal game version 1 shows the full range of income opportunities from competition. It has a most interesting quality: it contains a multiplicity of chicken games. A chicken game is an influential model of conflict for two players in game theory. The principle of the game is that although each player prefers not to yield to the other, the worst possible outcome occurs when both players do not yield (See Spaniel 2011). There are positive probabilities that it may evolve in at least four possible ways, so that the principal may adopt all of the possible strategies close to the deadline: reverting to the moral economy, competing savagely, or offering a dismal share. In response, the agent (DP) will respond with three possible strategies: closed lenient, closed severe, and open severe. Thus, three social preferences may evolve:

- $\mathrm{R}$, closed severe, which is equivalent to moral economy;

- C, closed lenient, or $\mathrm{C}$, open lenient, which are equivalent to competitive domination; and

- Coop, open severe, which is equivalent to coalition with the dying.

If each player has chosen a strategy and no player can benefit by changing strategies while the other players keep theirs unchanged, then the current set of strategy choices and the corresponding payoffs constitutes a Nash equilibrium (see Spaniel 2011). Note that $\mathrm{C}$ or Coop, closed severe, which is equivalent to revengeful collapse, is not a Nash equilibrium, which means that at least one of the players prefers an alternative strategic combination.
Because the structure of the game is a multiple chicken, the final results will depend on the highly irrational processes of the interaction of multiple players striving for their individual interests without having the means to coordinate and converge.

Dismal game version 2 has four Nash equilibria, but only two (Coop, open severe and Coop, open lenient) dominate over all others because they are Pareto efficient, i.e., they are in a state of allocation of resources in which it is impossible to make any one individual better off without making at least one individual worse off (see Spaniel 2011). Thus, we may hypothesize that the game will evolve in either direction. That is, we would expect the principal to always be willing to negotiate a share with the dying agent, because these strategic combinations allow for an internal negotiation of shares for premature death, therefore, in the matrix, there is a range of payoff possibilities. Although adopting these strategies, the principal aim is to absorb all the gains in efficiency caused by cooperation, but this is possible only under the Coop, open lenient equilibrium, which may give the agent the same payoff as the moral economy. However the Coop, open severe is not Nash in all the range of possible payoffs resulting from the negotiation. It has been argued that this is not a rational strategy because once the principal adopts Coop, the agent's best response is Coop, open lenient, so the threat of punishment is not credible. Thus it has been discarded as imperfect by classical game theory. However, such response has been amply analyzed by Gintis et al. (2000), Boyd (2003), and others and is now considered a crucial element of social behavior. Some people are willing to incur large costs to enforce equity, and the principal may not be able to differentiate between lenient and severe agents making precaution necessary, and a share of the gains will usually be offered to the agent.

In summary, from dismal game v. 1 we can expect the emergence of strategic combinations generating three of the social preferences, whereas from dismal game v. 2, we expect only one social preference, i.e., coalition with the dying, to evolve. Because we designed the spot games to inherit the basic structure of S2, we may expect similar differences to arise when there are cognitive, cultural, or educational variations in the groups of players, which restrict them from discovering the full range of competitive opportunities. With this intuition, we can return to our actual data to analyze what kind of game the academics and the farmers played in S2, and which strategies, strategic combinations, and equilibrium social preferences actually evolved. Were there any strategic or payoff differences between these groups, and if there were, how can we explain them?

\section{DATA ANALYSIS}

The experimental results presented come from 12 workshops held during 2012-2013, in which participated, separately, 116 rural smallholders, i.e., farmers, and 108 academics from socioenvironmental disciplines, i.e., graduate and postgraduate students, researchers, and professionals. Between December 2012 and July 2013, we held seven workshops with farmers and five with academics.

At the end of each game session, the players in each team worked together to record the final configuration of tokens on maps and photographs. The authors and their trained collaborators supervised and verified those activities for accuracy. Immediately 
after S2, each player filled out a written questionnaire in private, with the questions:

1. How many F, M, and I tokens did you place on rivers and in total?

2. What was the greatest number of points that you had at any time in the game, and what was your final point total? Did you die?

3. How many bonuses did you receive from each external actor?

4. During the last half of the game, were you ever in danger of dying?

5. If so, which of the following occurred:

- (a) Other players rearranged tokens or ceded sites to you so that you could occupy them and not die.

- (b) You died without ceding riparian sites to other players, and they did not offer any sort of compensation.

- (c) You died without ceding riparian sites to other players, and they offered to pay the fee for your cemetery plot. Did you accept?

- (d) Other players invited you to die and cede them some or all of your riparian sites in exchange for a fair share of the bonuses. Did you accept?

Game dynamics and attitudes of survivors and the dead were freely and respectfully discussed among players and researchers in collective debriefing and reflection sessions at the end of each workshop. We later calculated and compared the frequency of teams that attained moral economy in $\mathrm{S} 1$ and $\mathrm{S} 2$ and the ratio of dead players in both games. We counted the frequency of each possible way of dealing with the dying and the dead.

We confirmed that in S2, gameplay and emergent inequality evolved into three collective social preferences: moral economy, competitive domination, and coalition with the dying. Revengeful collapse was not observed. Based on the final board maps, photos, and questionnaires, we grouped farmer and academic teams, separately, according to the preference adopted, and we compared the distribution of social preferences across these two actors. The grouping criteria was based on analysis of team responses to question five: if (a), then moral economy; if (b) or (c), then competitive domination; if (d) and accept, then coalition with the dying; and revengeful collapse occurred if fixed rules (a) and (b) in section 2 were violated in the final board configuration.

For each of the 56 teams playing in S2, we ranked the 4 players according to the net amount of bonuses (NB) acquired. The player with the highest observed NB in a team was considered a principal and the one with the lowest, an agent. The NB was calculated per player by the following algebraic sum: bonus for hydrological services, if alive, plus bonuses for market provision, if alive, minus 2 bonuses for entry cost, alive or dead, minus 1 bonus for death cost, if dead. In the case of coalition, the algebraic sum of the NBs obtained by the principal and the agent was shared among them, according to each team's decision. In this experiment, all teams decided to share this sum in equal parts. We built the frequency distribution of NB per preference and actor. This was done separately for $\mathrm{NB}$ values of principals and agents. We compared observed NB distributions of principals across preferences and actors via box and whiskers graphs and chisquared tests ( $p<0.05$, in the program SPSS 15.0; Nie et al. 2006). The same was done for agents.

From each social preference, the maximum observed NB values for the principal, and associated NB values for the agent, were extracted to parameterize the spot game model. This result is presented as part of the discussion to explain the emergence of the observed social preferences.

\section{RESULTS}

During S1, players colonized sites cautiously, with little interaction at first. They usually began to communicate about issues concerning colonization of riparian sites after 5 minutes, and interaction intensified after 10 or 15 minutes when the deforestation table saturated. During S2, all farmer and academic teams hurried to place I tokens to occupy riparian sites and to effect deforestations. They saturated the deforestation table within three to five minutes. A typical game had four stages: (1) rapid colonization of sites; (2) disputes, open or veiled, over sites; (3) discovery and open recognition of the dilemma between rescuing the disadvantaged and earning more bonuses; and (4) settling a social preference to address the dilemma.

A study of Table 1 shows the following differences between death among farmers and academics, across S1 and S2:

Table 1. How players dealt with approaching death. A comparison across sessions and actors.

\begin{tabular}{|c|c|c|}
\hline & Farmers & $\begin{array}{l}\text { Acade- } \\
\text { mics }\end{array}$ \\
\hline Total number of players & 116 & 108 \\
\hline Total number of groups & 29 & 27 \\
\hline $\begin{array}{l}\% \text { of groups with one or more dead } \\
\text { players in session } 1\end{array}$ & 45 & 18 \\
\hline $\begin{array}{l}\% \text { of groups with one or more dead } \\
\text { players in session } 2\end{array}$ & 52 & 67 \\
\hline $\begin{array}{l}\text { Players that achieved }<24 \text { points. Ratio } \\
\text { session } 2 / \text { session } 1\end{array}$ & 1.00 & 3.60 \\
\hline $\begin{array}{l}\text { Players that achieved } 24 \text { points. Ratio } \\
\text { session } 2 / \text { session } 1\end{array}$ & 0.85 & 0.49 \\
\hline $\begin{array}{l}\% \text { of lagged players saved from imminent } \\
\text { death }\end{array}$ & 46 & 27 \\
\hline Dead in session 1 vs dead in session 2 & 17 vs 17 & 6 vs 21 \\
\hline$\%$ of dead that received no money & 44 & 20 \\
\hline $\begin{array}{l}\% \text { of dead that received unconditional } \\
\text { burial expenses }\end{array}$ & 45 & 5 \\
\hline $\begin{array}{l}\% \text { of dead that received conditional } \\
\text { (dismal) bonuses share }\end{array}$ & 11 & 75 \\
\hline
\end{tabular}

Of the teams of farmers, $45 \%$ had one or more deaths in S1, versus $52 \%$ in S2. Total deaths remained the same. Of the teams of academics, $18 \%$ had one or more deaths in S1, versus $67 \%$ in $\mathrm{S} 2$. The number of dead more than tripled. For both actors, any improvement in avoiding death caused by a learning effect was offset by other causes.

In S2, 33 farmers had < 24 points near the end of the game; $49 \%$ of them were "saved" through a coordinated team effort that, in the great majority of cases, required advantaged players to cede 
sites, and therefore bonuses. Of 29 academics in the same position, only $27 \%$ were saved.

In $\mathrm{S} 2$, of the 17 dead farmers, $11 \%$ reported that team members asked them to die and cede riparian sites in exchange for a fair share of the team's total bonuses and they all complied. Of the dead farmers, $45 \%$ said that team members offered, jointly, to pay the one-bonus death-cost for their coffin, a very low compensation, and $44 \%$ stated that their team members had either said nothing to them, or had said that they could do nothing for them, and that they, the dying, were responsible for being unable to earn 24 points. Of the 21 dead academics, $82 \%$ reported that team members asked them to die and cede riparian sites in exchange for a fair share of the team's total bonuses. Two of the dead declined the offer. Of the dead academics, $5 \%$ said that team members offered, jointly, to pay for their coffins, and $14 \%$ stated that their team members had either said nothing, or that they could do nothing for them.

In a significant number of academic game instances, the coalition with conditional help to the dying was the principal way in which the "win bonuses or rescue the dying" dilemmas were solved. Farmers rarely took this route, preferring instead to first compete and later make the effort to save the dying by surrendering some bonuses. When the farmers considered this solution either impossible or unjustifiable, they resolved the dilemma by ignoring the dying or by giving monetary aid unconditionally.

Table 2 shows that around half of farmer groups chose to attain moral economy in $\mathrm{S} 2$, and the preference for competitive domination was high, although a little less frequent than moral economy, but four times more frequent than the coalition preference. In contrast, in academic teams, the search for moral economy dropped from $82 \%$ to $33 \%$, and practically all the change occurred by switching to a coalition preference.

Table 2. Frequencies of different social preferences displayed by farmers and academics in sessions 1 and 2 .

\begin{tabular}{|c|c|c|}
\hline & $\mathrm{n}=29$ & $\mathrm{n}=27$ \\
\hline & $\begin{array}{l}\text { Farmer Teams } \\
\text { Percentage }\end{array}$ & $\begin{array}{c}\text { Academic Teams } \\
\text { Percentage }\end{array}$ \\
\hline \multicolumn{3}{|l|}{ Session 1} \\
\hline \multicolumn{2}{|l|}{ SixF } & 82 \\
\hline \multicolumn{3}{|l|}{ Session $2^{\dagger}$} \\
\hline Moral economy & 48 & 33 \\
\hline $\begin{array}{l}\text { Competitive } \\
\text { domination }\end{array}$ & 42 & 17 \\
\hline $\begin{array}{l}\text { Coalition with the } \\
\text { dying }\end{array}$ & 10 & 50 \\
\hline $\begin{array}{l}\text { Revengeful } \\
\text { collapse }\end{array}$ & 0 & 0 \\
\hline \multicolumn{3}{|c|}{$\begin{array}{l}{ }^{\dagger} \text { Chi square test }\left(\mathrm{X}^{2}=47.9, \text { d.f. } 2, \mathrm{p}<0.0001\right) \text { was conducted } \\
\text { to compare farmers' vs academics' frequencies in session } 2 \text {. } \\
\text { Revengeful collapse was not included in the comparison } \\
\text { because there were zero cases. }\end{array}$} \\
\hline
\end{tabular}

Figure 5 shows that the observed distribution of net bonuses (NB) attained by the principals did not differ statistically across actors or social preferences (i.e., Chi-square-derived $\mathrm{p}$ values were $>$ $0.05)$. Yet, farmer principals achieved marginally higher NB than academic principals in competitive domination $\left(\mathrm{X}^{2}=4.26\right.$, d.f. 1 ; $P=0.08)$. Figure 6 shows that NB values per social preferences did not differ across actors. For both actor' agents, NB was higher for moral economy than for competition (farmers: $X^{2}=26$, d.f. 6; $\mathrm{P}<0.001$; academics: $\left.\mathrm{X}^{2}=14, \mathrm{P}=0.001\right)$, and $\mathrm{NB}$ was higher for coalition than for the other two preferences (farmers: $\mathrm{X}^{2}=58$, d.f. 6; $\mathrm{P}<0.001$; academics $\mathrm{X}^{2}=42$, d.f. $6 ; \mathrm{P}<0.001$ ).

Fig. 5. Distribution of observed principals' payoffs in net bonuses (NB) across three social preferences and across two actors, academics and farmers. Net bonuses frequency distributions are compared graphically with box and whiskers quartiles. See $\mathrm{X}^{2}$ comparisons in the main text.

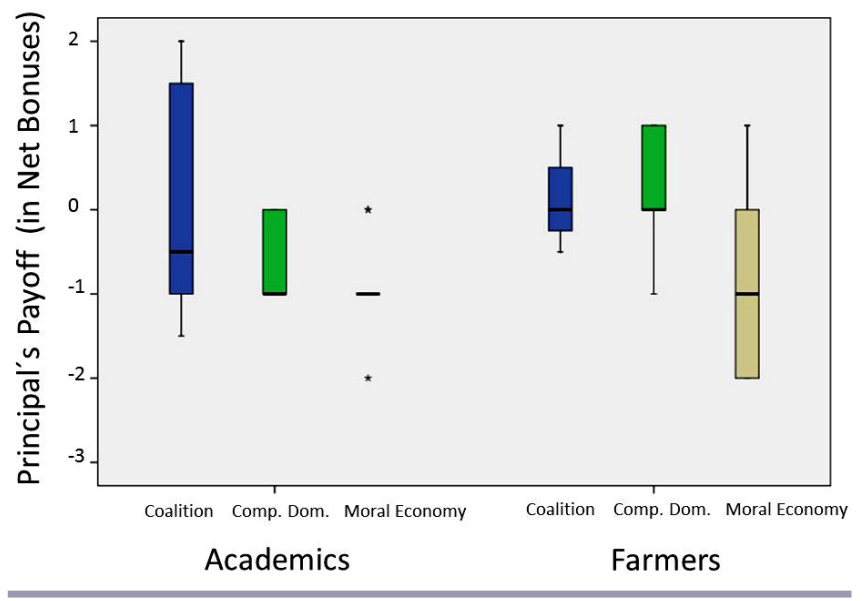

Fig. 6. Distribution of observed agents' payoffs in net bonuses (NB) across three social preferences and across two actors, academics and farmers. Net bonuses frequency distributions are compared graphically with box and whiskers quartiles. See $\mathrm{X}^{2}$ comparisons in the main text.

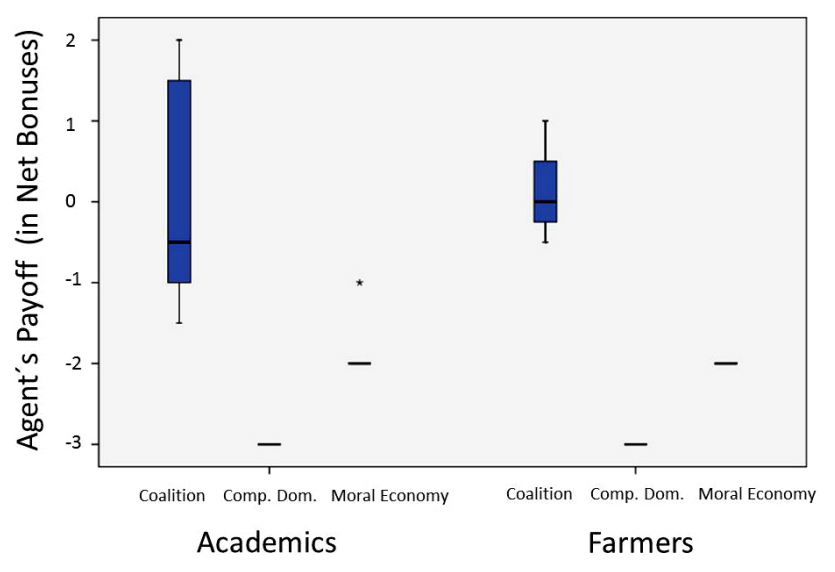


During debriefing, participants most frequently focused on S2. We report qualitative observations pooled for farmers and academics. Regarding how participants dealt with emerging inequity, in teams that reverted to the moral economy preference, "saviors" expressed with great pride and satisfaction how they gave up some bonuses to rescue others. "The saved" were less enthusiastic about telling their story. In teams that did not revert, "survivors" were vocal only when they had formed coalitions to share bonuses. Disadvantaged players who accepted coalitions rarely complained openly and some showed satisfaction. Those subject to competitive domination did express their feelings with shame and confusion or with clarity and contained anger. Some blamed themselves, but were proud to tell us that they had refused to seal the inequality by accepting charity or by allowing the winners to accumulate means of production from their misfortune, therefore they chose death. Others had assumed a more submissive position in a permanent hierarchy and accepted charity or dispossession of land for bonus sharing. Both kinds of players showed shame during the debriefing. Attribution of blame to the other players was much more common. In this case, there were four main reactions. Some angrily explained that during the game they rejected the coalition proposal and demanded that other players sacrifice for equity or sustainability; others had accepted compensation or negotiation as a fair retribution and a means toward equality; and some had reacted angrily to the offer, preferring to die. Although all the behaviors were present between both experimental groups, we noted that among the rural small holders offering unconditional help was more common than offering compensatory deals, whereas the different kinds of reactions were more widespread among the academics.

\section{DISCUSSION AND CONCLUSIONS}

The payoff matrix shown in Figure 7 summarizes the results of our experiment in a way that allows us to compare these results with those expected from our spot-game analysis. Clearly, once inequity appeared in S2 because of the struggle to coordinate, survive, and profit, participants actually split into advantaged and disadvantaged players, the latter with a high probability of dying. Our results suggest that players also discovered all the strategies described in our analysis and that the players' teams could combine them in the five different strategic combinations, which, as a matter of fact, are described by the union of the equilibria of both V. 1 and V. 2 of the dismal game. Thus, none of the spot games appears to be sufficient to explain our results. Because V. 1 allows for four of the five possible equilibria, we could claim the experimental results appear to correspond more with it. However, this confronts us with a dilemma, because advantaged players clearly did not discover the full range of payoffs from the competitive strategy, nor for that matter from any other strategy (compare fig. 3 and 5), so the game's true structure cannot be represented by such a version. Meanwhile, dismal game v. 2, although allowing for a reduced range in the profits and for the fifth equilibria to emerge, cannot explain why some advantaged players reverted to the moral economy or stuck to the competitive domination mode. Theoretically, the latter difficulty could be surmounted if the Coop strategy is removed from the principal choices in dismal game v. 2. This makes sense if such a strategy is cognitively or emotionally difficult to attain. In this case, the game is further reduced to a chicken game with no efficient solution, and both nonefficient Nash equilibria can evolve empirically. We may surmise that this was the case with most farmer teams, whereas many academics could profit from the advantages of new choices involving strategic cooperation. However, we must take into account that we are dealing with situations in which cooperation involves outcompeting and then killing your partner. Thus, advantaged players may understand the advantages of strategic cooperation only if they previously understood the opportunities of competition. Thus, although increasing the profitability of the strategies is a process of discovery for all players, the maximum payoffs expected from cooperation will be positively correlated to but smaller than the maximum payoff from pure competition. This will tend to maintain the multiple chicken structure of the game. Therefore, we may conclude that the few farmer and many academic teams that took advantage of the Coop strategy could have been playing similarly to dismal game v. 1, while (unsuccessfully) struggling to increase their profits. Thus, it seems that to explain our experimental results, we will need a more real-life-messy approach in which the players are restricted but fight against their actual cognitive and emotional restrictions. That is, we think players in S2 struggled, both cognitively and emotionally, to understand games similar to versions 1 or 2 , and to adopt one of them. Such struggles are easier to grasp if instead of interpreting the strategies of AP and DP as simple choices, we think of them as partially substitutable behavioral propensities that are responsive to the context (see context effects in DeScioli and Krishna 2013, Farolfi et al. 2014). Consider as well that game theory doesn't account for the contextual effect of continued postgame interactions and payoffs in the games that continue after the experiment among players who know each other in daily life.

Fig. 7. Payoff matrix of highest net bonuses attained by a principal and associated agent payoffs. Pairs in bold are the Nash equilibria that actually emerged empirically in the experiment. Note that all equilibria of the dismal game v. 1 and v. 2 were observed experimentally. Pairs in light gray are nonequilibria strategic combinations, common to versions 1 and 2 of the dismal game; they were not observed.

\begin{tabular}{|c|c|c|c|c|}
\hline \multirow{2}{*}{} & \multicolumn{3}{|c|}{ PRINCIPAL } \\
\cline { 3 - 5 } & $\begin{array}{c}\mathrm{R} \text { (revert to no } \\
\text { deaths) }\end{array}$ & $\begin{array}{c}\mathrm{C} \text { (continue to } \\
\text { compete) }\end{array}$ & $\begin{array}{c}\text { Coop (negotiate } \\
\text { and share) }\end{array}$ \\
\cline { 2 - 5 } & $(-2,1)$ & $(-3,1)$ & $(-3,1)$ \\
\hline \multirow{2}{*}{\begin{tabular}{c} 
Closed lenient (survive) \\
\cline { 2 - 4 }
\end{tabular}} & $\begin{array}{c}\text { Closed severe (if } \mathrm{R}, \\
\text { survive; if not R, then } \\
\text { punish) }\end{array}$ & $(-2,1)$ & $(-3,-3)$ & $(-3,-3)$ \\
\cline { 2 - 5 } & $\begin{array}{c}\text { Open lenient (if not } \\
\text { Coop, survive; if Coop, } \\
\text { then Coop) }\end{array}$ & $(-2,1)$ & $(-3,1)$ & $(2,2)$ \\
\cline { 2 - 5 } & $\begin{array}{c}\text { Open severe (if R, } \\
\text { survive; if C, punish; if } \\
\text { Coop, and share } \\
\text { accepted, then Coop; if } \\
\text { not, then punish) }\end{array}$ & $(-2,1)$ & $(-3,-3)$ & $(2,2)$ \\
\hline
\end{tabular}

We can now discuss differences among farmers and academics. Context-driven social preferences must show further stability and resilient properties that allow them to more or less resist uncertain environments. In part, such resistance may arise from the dynamics of cognition. We have conjectured about the possibility that farmers got stuck in S2 in a kind of chicken game between 
the moral economy equilibrium and the competitive domination equilibrium. This may be caused by their problem discovering and/or applying a dismal cooperative strategy. Among others, this could be a consequence of their difficulty to adapt on such short notice to the rules of the academic environment, which is based on instruction following and a problem-solving rationale. That would explain why $45 \%$ of the teams of farmers had one or more deaths in S1, compared to only $18 \%$ of the academic teams. However, cognitive dynamics not only stabilize social preferences by increasing adaptation costs to new/unknown environments, but also by inducing cognitive dissonance (Festinger 1964) that may steer players, in our case, farmers mainly, to select new information and solve new problems according to previously established preferences that do not include a dismal cooperative strategy.

We have shown a strong difference regarding the frequency with which farmers and academics have evolved the three social preferences in S2. Around half of the farmer teams chose to attain moral economy, although their preference for competition remained much higher than their cooperative preference. Their first response was to compete and then later make the effort to save the dying by surrendering some bonuses, but when they considered this solution either impossible or unjustifiable, they resolved the dilemma by ignoring the dying or by paying for their coffins, a common although desperate form of moral economy among the poor that in the case of the game was also their choice to prevent revengeful collapse and postgame tensions among players who would continue to interact in their daily lives. In contrast, the academic teams dropped their search for moral economy as they evolved a coalition, a form of strategic cooperation (García-Barrios et al. 2008). Some academic DP rejected this cooperative proposal and continued struggling because they would not allow the advantaged players to accumulate means of production from their misfortune. However, most AP and DP involved in a coalition with the dying social preference were relatively happy with such an outcome. The coalition had the role of a last-resort choice, a win-win solution, which allowed DP some final leverage and AP to use liberated resources to improve efficiency. This type of solution is currently part of the repertoire for strategic cooperation among the unequal in poverty stricken territories (García-Barrios et al. 2008). It's part of the culture in which academics are being educated as sustainability professionals and toward which farmers are being steered. In the stringent socio-environmental conditions of this game, it resulted in a Pareto-superior form of equity, albeit with land surrendering and many more deaths than other preferences.

Social preferences have most commonly been analyzed through game theory and highly controlled lab experiments (DeScioli and Krishna 2013). Role-playing games are more realistic and deal with social preferences with an extensive number of rules, variables, and stakeholders in a very adaptive and open-ended way (Lynam 2007). The cost is that it becomes difficult to reproduce the results and to make systematic comparisons because many factors are uncontrolled (Bousquet et al. 2002). Furthermore, there are additional trade-offs (and therefore debate) in terms of context dependency, framing, and internal and external validity of results (DeScioli and Krishna 2013, Gelcich et al. 2013, Farolfi et al. 2014). We contend that the Sierra Springs platform and the game described here combine the three approaches and help counter, to a certain extent, some of these trade-offs (García-Barrios et al. 2011). However, there is a need for caution and ample room for improvement.

The study of the emergence of social preferences in complex rural situations will need further investigation. Lab and field experiments, agent-based models, and role-playing games have looked, mainly through common-pool resource and public-good games, at how the interplay of uncertainty, costly sanctions, diverse types of incentives, trust, communication, and context can conduce to different levels of fragility in cooperation among those with unequal power and/or resources, and to less or more inequity (Cox et al. 2011, Janssen et al. 2011, Narloch et al. 2012, Perez et al. 2012, Abou Chakra and Traulsen 2014). Results and methods from our work and from these and other approaches and efforts can be further advanced, debated, and used to facilitate communication among farmers, academics, and local policy operators. This could help all to become better aware of the social preferences that we are evolving together in tropical mountains, and similar territories, and their potential social and environmental consequences. In a broader geographical and thematic perspective, these efforts can contribute to the recent calls (Moore et al. 2014) to build more robust tools for actors who are deliberately trying to escape from human-environmental interactions that have become locked in to unsustainable pathways (Folke et al. 2010) and who need to navigate the tensions that emerge in such deliberate transformation processes.

Responses to this article can be read online at: http://www.ecologyandsociety.org/issues/responses. $\mathrm{php} / 7372$

\section{Acknowledgments:}

We thank the 224 players for their voluntary and enthusiastic participation; Romeo Trujillo and Adriana Flores for assisting with workshops in the Sierra Madre; and Balente Herrera and Jorge Urdapilleta in the Northern Sierra. We also thank Elisabeth HuberSannwald, Manuel Parra, Carlos Gonzalez, Mario González, Jorge López, Maria Elena Martinez, and the Alfa III SERIDAR-(EU) project for sponsoring some of the workshops, and Marco Janssen, Meine van Noordwijk, Beria Leimona, and Betha Lusiana for sponsoring discussion in the early stages of this research. We thank three anonymous reviewers whose many comments and suggestions greatly improved the manuscript.

\section{LITERATURE CITED}

Abou Chakra, M., and A. Traulsen. 2014. Under high stakes and uncertainty the rich should lend the poor a helping hand. Journal of Theoretical Biology 341:123-130 http://dx.doi.org/10.1016/j. jtbi.2013.10.004

Anderies, J. M., M. A. Janssen, F. Bousquet, J.-C. Cardenas, D. Castillo, M.-C. Lopez, R. Tobias, B. Vollan, and A. Wutich. 2011. The challenge of understanding decisions in experimental studies of common pool resource governance. Ecological Economics 70 (9):1571-1579. http://dx.doi.org/10.1016/j.ecolecon.2011.01.011 
Barreteau, O., C. Le Page, and P. D'Aquino. 2003. Role-playing games, models and negotiation processes. Journal of Artificial Societies and Social Simulations 6(2):10. [online] URL: http:// jasss.soc.surrey.ac.uk/6/2/10.html

Bousquet, F., O. Barreteau, P. d'Aquino, M. Étienne, S. Boissau, S. Aubert, C. Le Page, D. Babin, and J.-C. Castella. 2002. Multiagent systems and role games: collective learning processes for ecosystem management. Page 248-285 in M. A. Janssen, editor. Complexity and ecosystem management: the theory and practice of multi-agent systems. Edward Elgar, Cheltenham, UK.

Bowles, S. 2008. Policies designed for self-interested citizens may undermine "the moral sentiments": evidence from economic experiments. Science 320:1605-1609. http://dx.doi.org/10.1126/ science. 1152110

Boyd, R., H. Gintis, S. Bowles, and P. J. Richerson. 2003. The evolution of altruistic punishment. Proceedings of the National Academy of Sciences 100(6):3531-3535. http://dx.doi.org/10.1073/ pnas. 0630443100

Chappell, M. J., H. Wittman, C. M. Bacon, B. G. Ferguson, L. García-Barrios, R. García-Barrios, D. Jaffee, J. Lima, V. E. Méndez, H. Morales, L. Soto-Pinto, J. Vandermeer, and I. Perfecto. 2013. Food sovereignty: an alternative paradigm for poverty reduction and biodiversity conservation in Latin America. F1000 Research 2:235. http://dx.doi.org/10.12688/ f1000research.2-235.v1

Corbera, E., and U. Pascual. 2012. Ecosystem services: heed social goals. Science 335:655-657. http://dx.doi.org/10.1126/science.335.6069.655$\underline{\mathrm{c}}$

Cortina, J. 2014. Subsidizing migration? Mexican agricultural policies and migration to the United States. Policy Studies Journal 42(1):101-121. http://dx.doi.org/10.1111/psj.12044

Cox, J. C., E. Ostrom, and J. M. Walker. 2011. Bosses and kings: asymmetric power in paired common pool and public good games. No 2011-06, Experimental Economics Center working paper series. Georgia State University, Atlanta, Georgia, USA. [online] URL: https://ideas.repec.org/p/exc/wpaper/2011-06.html

Cruz-Morales, J. 2014. Desafíos para construir la democracia ambiental en la Cuenca Alta del Río El Tablón (CART), Reserva de la Biosfera La Sepultura (REBISE), Chiapas, México. Pages 21-60 in M. del C. Legorreta Díaz and C. Márquez Rosano, editors. Paradojas de las tierras protegidas en Chiapas. CEIICHCRIM-UNAM, Mexico City, Mexico, and DCRU-UACh, Chiapas, Mexico.

DeScioli, P., and S. Krishna. 2013. Giving to whom? Altruism in different types of relationships. Journal of Economic Psychology 34:218-228. http://dx.doi.org/10.1016/j.joep.2012.10.003

Etienne, M., editor. 2014. Companion modelling: a participatory approach to support sustainable development. Springer, Berlin, Germany and Éditions Quæ, Versailles, France.

Farolfi, S., M. Désolé, and P. Rio. 2014. Influence of context on player behavior: experimental assessment. Simulation and Gaming 45:627-665 http://dx.doi.org/10.1177/1046878114563647

Fehr, E., and S. Gächter. 2002 a Do incentive contracts undermine voluntary cooperation? Working Paper No. 34. Institute for
Empirical Research in Economics. University of Zurich, Zurich, Switzerland. http://dx.doi.org/10.2139/ssrn.313028

Fehr, E., and S. Gächter. 2002b. Altruistic punishment in humans. Nature 415:137-140 http://dx.doi.org/10.1038/415137a

Festinger, L. 1964. Conflict, decision, and dissonance. Stanford University Press, Stanford, California, USA.

Fiske, A., and N. Haslam. 2005. The four basic social bonds: structures for coordinating interaction. Pages 267-298 in M. W. Baldwin, editor. Interpersonal cognition. Guilford, New York, New York, USA.

Folke, C., S. R. Carpenter, B. Walker, M. Scheffer, T. Chapin, and J. Rockström. 2010. Resilience thinking: integrating resilience, adaptability and transformability. Ecology and Society 15(4): 20. [online] URL: http://www.ecologyandsociety.org/vol15/iss4/ $\underline{\operatorname{art} 20 /}$

García-Barrios, R., B. de la Tejera Hernández, and K. Appendini. 2008. La cooperación estratégica: una introduccón al debate. Pages 17-32 in R. García-Barrios, B. de la Tejera Hernández, and K. Appendini, editors. Instituciones y desarrollo: ensayos sobre la complejidad del campo mexicano. CRIM-UNAM/El Colegio de México/Universidad de Chapingo, Mexico City, Mexico.

García-Barrios, L., R. García-Barrios, A. Waterman, and J. CruzMorales. 2011. Social dilemmas and individual/group coordination strategies in a complex rural land-use game. International Journal of the Commons 5(2):364-387. [online] URL: http://www.thecommonsjournal.org/index.php/ijc/article/view/289/223

Gelcich, S., R. Guzman, C. Rodriguez-Sickert, J. C. Castilla, and J. C. Cérdenas. 2013. Exploring external validity of common pool resource experiments: insights from artisanal benthic fisheries in Chile. Ecology and Society18(3): 2. http://dx.doi.org/10.5751/ ES-05598-180302

Gintis, H. 2000. Game theory evolving: a problem-centered introduction to modeling strategic behavior. Princeton University Press, Princeton, New Jersey, USA.

Graeber, D. 2011. Debt: the first 5000 years. Mellville House, New York, New York, USA.

Hiedanpää, J., and D. W. Bromley. 2014. Payments for ecosystem services: durable habits, dubious nudges, and doubtful efficacy. Journal of Institutional Economics 10:175-195. http://dx.doi. org/10.1017/S1744137413000428

Janssen, M. A., J. M. Anderies, and S. R. Joshi. 2011. Coordination and cooperation in asymmetric commons dilemmas. Experimental Economics. 14:547-566. http://dx.doi. org/10.1007/s10683-011-9281-9

Klepeis, P., and C. Vance. 2003. Deforestation and neoliberal policy in southeastern Mexico. An assessment of the PROCAMPO program. Economic Geography 79:221-240 http:// dx.doi.org/10.1111/j.1944-8287.2003.tb00210.x

Liverman, D. M., and S. Vilas. 2006. Neoliberalism and the environment in Latin America. Annual Review of Environment and Resources 31:327-363. http://dx.doi.org/10.1146/annurev. energy.29.102403.140729 
Lynam, T., W. de Jong, D. Sheil, T. Kusumanto, and K. Evans. 2007. A review of tools for incorporating community knowledge, preferences, and values into decision making in natural resources management. Ecology and Society 12(1): 5. [online] URL: http:// www.ecologyandsociety.org/vol12/iss1/art5/

Moore, M.-L., O. Tjornbo, E. Enfors, C. Knapp, J. Hodbod, J. A. Baggio, A. Norström, P. Olsson, and D. Biggs. 2014. Studying the complexity of change: toward an analytical framework for understanding deliberate social-ecological transformations. Ecology and Society 19(4): 54. http://dx.doi.org/10.5751/ ES-06966-190454

Narloch, U., U. Pascual, and A. G. Drucker. 2012. Collective action dynamics under external rewards: experimental insights from Andean farming communities. World Development 40:2096-2107. http://dx.doi.org/10.1016/j.worlddev.2012.03.014

Nie, N., D. Bent, and H. Hull. 2006. SPSS for Windows. SPSS Inc., Chicago, Illinois, USA.

Pascual, U., J. Phelps, E. Garmendia, K. Brown, E. Corbera, A. Martin, E. Gomez-Baggethun, and R. Muradian. 2014. Social equity matters in payments for ecosystem services. Bioscience 64 (11):1027-1036. http://dx.doi.org/10.1093/biosci/biu146

Pérez, I., J. A. Baggio, N. D. Rollins, and M. A. Janssen. 2012. Cooperation in asymmetric commons dilemmas. CSID Working Paper Series. Center for the Study of Institutional Diversity, Tempe, Arizona, USA. [online] URL: http://csid.asu.edu/sites/ csid.asu.edu/files/csid wp 2012-012 0.pdf

Sandker, M., B. M. Campbell, M. Ruiz-Pérez, J. A. Sayer, R. Cowling, H. Kassa, and A. T. Knight. 2010. The role of participatory modeling in landscape approaches to reconcile conservation and development. Ecology and Society 15(2): 13. [online] URL: http://www.ecologyandsociety.org/vol15/iss 2/ $\underline{\operatorname{art13/}}$

Schmook, B., and C. Vance. 2009. Agricultural policy, market barriers, and deforestation: the case of Mexico's Southern Yucatán, World Development 37:1015-1025. http://dx.doi. org/10.1016/j.worlddev.2008.09.006

Scott, J. C. 1977. The moral economy of the peasant: rebellion and subsistence in Southeast Asia. Yale University Press, New Haven, Connecticut, USA.

Spaniel, W. 2011. Game theory 101 the basics. Electronic book . Kindle Edition. Rochester, New York, New York, USA.

Speelman, E. N., L. E. García-Barrios, J. C. J. Groot, and P. Tittonell. 2014b. Gaming for smallholders' participation in the design of more sustainable agricultural landscapes. Agricultural Systems 126:62-75 http://dx.doi.org/10.1016/j.agsy.2013.09.002

Speelman E. N., J. C. J. Groot, L. E. García-Barrios, K. Kok, H. van Keulen, and P. Tittonell. 2014a. From coping to adaptation to economic and institutional change - trajectories of change in land use management and social organization in a biosphere reserve community, Mexico. Land Use Policy 41:31-44. http://dx. doi.org/10.1016/j.landusepol.2014.04.014

Tadelis, S. 2013. Game theory: an introduction. Princeton University Press, Princeton, New Jersey, USA.
Villamor, G. B., and M. van Noordwijk. 2011. Social role-play games vs individual perceptions of conservation and PES agreements for maintaining rubber agroforests in Jambi (Sumatra), Indonesia. Ecology and Society 16(3): 27. http://dx. doi.org/10.5751/ES-04339-160327

Wunder, S. 2006. Are direct payments for environmental services spelling doom for sustainable forest management in the tropics? Ecology and Society 11(2): 23. [online] URL: http://www. ecologyandsociety.org/vol11/iss2/art23/ 


\section{Appendix 1. \\ Workshops}

The experimental results presented here come from 12 workshops held during 2012-2013, in which participated (separately) 116 rural smallholders (farmers) and 108 academics from socio-environmental disciplines (graduate and postgraduate students; researchers, and professionals). Between December 2012 and July 2013, we did seven workshops with farmers, and five with academics. In no case did the players of different workshops have the opportunity to communicate with each other before participating. The farmers came from the full range of socioeconomic levels that are present in the mountains of tropical southern Mexico. Six of the workshops with farmers included participants from 12 communities in Sierra de Villaflores (in Chiapas's Sierra Madre); the seventh was given to persons from six communities in Chiapas's Sierra Norte. Participants from the first six workshops were 84 native Spanish speakers who raised cattle, corn, and coffee on 5 to 30 ha. (Therefore, they are considered small and medium producers.) All of the farmers in the seventh workshop were native Tsotsil (Maya) speakers who raised cattle, corn, and coffee on 2 to 5 ha. (They are considered small producers.) In terms of social organization, the native Spanish speakers are organized loosely around the political party in power, whereas the native Tsotsil speakers are from communities organized strongly around a Jesuit mission. Their ages ranged from 20 to 65 years, with a mode of approximately 35 years. In each workshop, participants played "let's make a snake" to order themselves from oldest (the head) to youngest (the tail); its body was then segmented into 4-player teams to reduce age-difference hierarchies within them. The authors and/or their colleagues have maintained close relations of participatory action research with both teams of farmers for over five years.

All five of the workshops with academics were held during short, intensive courses on the evaluation of sustainability and/or complex sociological processes. Ages also ranged from 20 to 65 years, with a mode of approximately 28 years. Socioeconomically, they represented levels from students who were just beginning their master's degrees, to seasoned, internationally renowned Mexican researchers. Professionals with master's degrees predominated. The academics' disciplines included anthropology, sociology, economy, biology, ecology, and environmental engineering oriented toward public and private enterprises. Because of the nature of the investigation, we maintain the anonymity of all workshops and participants. Information is available upon justified request, with proper safeguards.

After the players had listened to Sierra Springs' fixed rules and tried them out in detail on the board, the investigators presented the rules of Session 1 in the form of the following fictional, but plausible, narrative that established a stylized context for the game: 
We are in the year 1960. You are four young adults, children of local farmers, and the assembly of local property owners meets with you to assign you tracts of land in an uncolonized, forested part of the community that has the initial forested configuration described in the fixed rules. The assembly assigns a quadrant to each of you, and informs you of the environmental limits and the rules for colonizing sites in riparian borders. In addition, the assembly imposes two social rules that must be followed scrupulously:

(a) Moral Economy Rule: In this community, we live by the principle of moral economy: each of you may earn as much as you wish (i.e., gain as many points as you wish) from your quadrant and its riparian borders, in any way you wish, as long as you ensure that no one dies for having failed to earn the minimum living (24 points) necessary for survival.

(b) SixF Rule: Because of environmental limits, at least 16 of the 48 sites in the territory that has been assigned to you must remain under forest management. For the good of the community, two of you must specialize in managed forestry so that the community can be supplied with forest products efficiently, from sites that are not inconveniently dispersed (i.e. two players must place all their F tokens on their quadrants).

If either of these rules is violated, each of you who survive must pay a fine of 1.5 USD, then leave the community to make a life elsewhere. (You become socially dead to the community). The family of each person (i.e., player) who dies will have to pay a fee of 1.5 USD for a cemetery plot. At the end of the game, the game coordinator will collect any fines and fees.

Each table of participants played one game under the above rules; they were allowed to talk freely, but only to their team members. After a 20-minute rest, a second game was announced. They return to the same positions that they occupied during session 1 . In preparation for session 2, the time limit was reset to 50 minutes, and the initial, forested condition of the Sierra Springs game board was reestablished.

Session 2 retained the fixed rules conditions. However, the game coordinator began with the following narrative that rescinded Session 1's institutional rules and introduced new ones:

We are in the year 2010. You are four young adults. The environmental limits and landuse restrictions are the same as in 1960. However, the authority of the local assembly has weakened, and the institutional rules ME+SixF of Session 1 are no longer obligatory. To satisfy the domestic and international demand for so called (forest dependent) hydrological services and provision services (livestock), the external actors offer individual monetary incentives to induce famers to use their land in specific ways. The local authorities meet with you to assign you tracts of land in an uncolonized, forested part of the community that has the initial forested configuration described in the fixed rules. The authorities assign a quadrant to each of you, and inform you of the 
environmental limits for colonizing sites in riparian borders. Then, you are informed that

(a) The ME principle is no longer in effect. If someone dies, her family must pay a fee of 1.5 USD for a cemetery plot. Survivors are no longer expelled from the community. Whether you help others survive or not is now your personal decision, and will be respected by the community. Thus, moral economy is no longer a norm but a free option.

(b) If you survive (i.e., if you have 24 points at the end of the game), and have established managed forestry on six sites, you will receive a 1.5 USD bonus in payment for hydrological services.

(c) If you survive, you will receive a bonus of 1.5 USD for each point that you earned in excess of the 24 needed for survival.

(d) If you meet the requirements for both (b) and (c), you will receive both payments.

(e) There is a relatively high transaction cost for local actors of interacting with the external actors that provide bonuses. Therefore, each player incurs a cost of 3.0 USD which she must pay upfront to the game coordinator.

The authors took participants' circumstances into consideration when setting the amount of the entry cost at 3 USD. Academics were told one day ahead of time that they would need to pay that amount if they wished to participate. Farmers - who would spend a full workday traveling to the workshop and participating in it-were told at the beginning of the workshop that those who played would receive only 3 USD rather than the 6 USD that they would normally make for a day spent working for a wage. At the request of the leaders of their communities, we gave farmers from the Sierra Norte 3 USD in chocolates rather than in cash. We paid their bonuses in chocolates as well.

To maintain consistency, the first author was the game coordinator in every workshop. Each workshop lasted four and one-half hours: one hour for explaining and demonstrating the game; two and a half for playing the game and collecting data; and one hour for paying bonuses, exchanging information, and reflecting as a group upon the results. Players were free to talk within their teams all the time. Rules were clarified for them upon request

At the end of each game session, the players in each team worked together to record the final configuration of tokens on maps, in orthogonal photographs, and in individual, confidential questionnaires. The authors and their trained collaborators supervised those activities, made photos of board-game outcomes, verified the point totals earned by each player and team, and checked the maps and questionnaires for accuracy.

Immediately after $\mathrm{S} 2$, each player filled out a written questionnaire in private (see DATA ANALYSIS in the main text). 


\section{Appendix 2. \\ Description of procedure for identifying the Outcome Set for Sierra Springs for ME}

Under ME, the SS game can be analyzed as a puzzle that combines arithmetic and geometric elements. Because of the interacting, multi-scale effects of its rules, SS lends itself to solution through use of a combination of constraint-propagation and searches (much like Sudoku).

Many of the constraints that we used in identifying SS's outcome set result from the riparian zones' restrictive environmental and spatial conditions. Players cannot avoid competing in those zones if they are to earn at least the subsistence living. From the constraints upon players' riparian-zone options, other constraints can be inferred to reduce the search space to a manageable size.

Configurations of tokens that satisfy ME can be classified according to different frameworks. The framework that we used is that an outcome is a legal riparian colonization to which four additional sets of tokens - one set for each quadrant interior - have been "fitted" to produce a configuration that satisfies ME. The outcome-identification procedure that we based upon this framework was, broadly, as follows:

1. Identify and list all of the legal riparian colonizations.

2. For each legal riparian colonization, identify the sets of four quadrant-interior colonizations that, when used in combination with the riparian colonization under consideration, satisfy ME.

3. From the list of combinations of riparian and quadrant-interior colonizations generated in Steps 1 and 2, eliminate any that (when deployed on the SS board) are rotations, reflections, or inconsequential rearrangements of each other.

The list of combinations that results from Steps 1 through 3 is the outcome set for ME. The same riparian constraints that make SS amenable to solution via that procedure make the framework that we employed useful for understanding the players' forms of coordination and competition. Some terms (and corresponding acronyms) chosen for describing outcomes according to that framework are used in Figure 2a (reproduced here for the reader's convenience).

- Riparian Triad (RT): The set of tokens placed on riparian sites by a single player.

- Complete Triad (CT): The complete set of tokens placed by a single player. (Includes those placed on both riparian and quadrant-interior sites).

- Outcome (Sometimes referred to in this paper as a "Board"): An arrangement of tokens that satisfies ME. All arrangements that are reflections, rotations, or trivial rearrangements of each other are classified as the same outcome.

Note that Figure $2 b$ of the main text is not an outcome since it does not give 24 points to each player. 
Fig. 2. Schematic diagrams of the SS game board, showing results that give the maximum possible number of bonuses for the group of four players under two different conditions: (a) Obligatory ME, and (b) no obligation to achieve ME. Lines drawn around each quadrant enclose the tokens placed by each player. In (b), players 1 and 3 have been ceded control of all of the riparian sites that are available to them. $\mathrm{RT}=$ The set of tokens that the player has placed on riparian sites. (Format is [<number of $\mathrm{F}$ tokens $\rangle$, <number of Ms $\rangle$, <number of Is $>$ ].) $\mathrm{CT}=$ The complete set of tokens that the player has used. (Format is the same as for RTs.) Total Bonuses = sum of PES and PB. PB =Provision Bonus (equal to the number of points earned in excess of the 24 needed for survival). (Note that (b) is not an outcome because it does not give 24 points to each player.)

(a) ME plus 4 bonuses

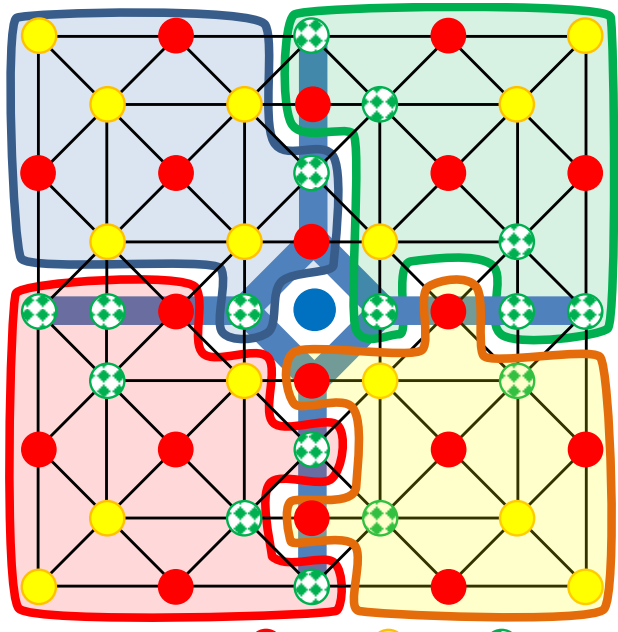

Tokens: $\mathrm{I} \bigcirc \mathrm{M} \bigcirc \mathrm{F} \odot$

\begin{tabular}{|l|c|c|c|c|}
\cline { 2 - 5 } \multicolumn{1}{c|}{} & \multicolumn{4}{c|}{ Player } \\
\cline { 2 - 5 } \multicolumn{1}{c|}{} & 1 & 2 & 3 & 4 \\
\hline RT [F,M,I] & {$[2,0,1]$} & {$[4,0,1]$} & {$[0,0,3]$} & {$[4,0,1]$} \\
\hline TC [F,M,I] & {$[2,5,4]$} & {$[6,3,4]$} & {$[2,3,6]$} & {$[6,3,4]$} \\
\hline Points & 24 & 24 & 26 & 24 \\
\hline $\begin{array}{l}\text { Total } \\
\text { bonuses }\end{array}$ & 0 & 1 & 2 & 1 \\
\hline PES & 0 & 1 & 0 & 1 \\
\hline PB & 0 & 0 & 2 & 0 \\
\hline
\end{tabular}

(b) Maximum possible

bonuses if ME not met

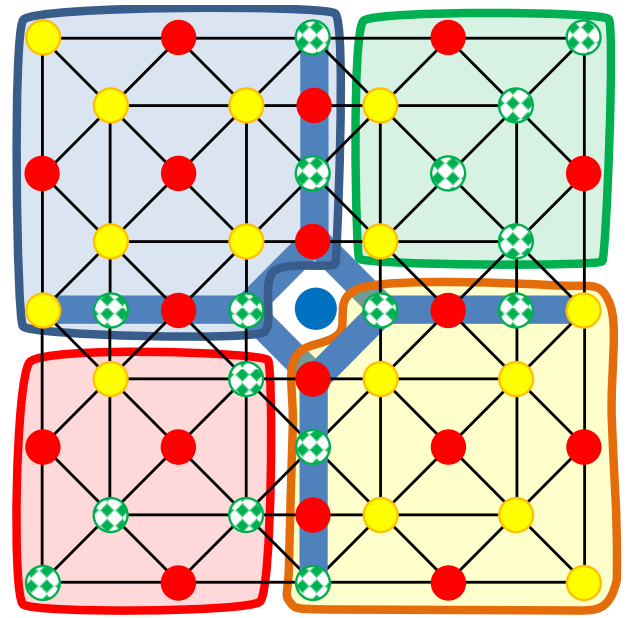

\begin{tabular}{|l|c|c|c|c|}
\cline { 2 - 5 } \multicolumn{1}{c|}{} & \multicolumn{4}{c|}{ Player } \\
\cline { 2 - 5 } \multicolumn{1}{c|}{} & 1 & 2 & 3 & 4 \\
\hline RT $[F, M, I]$ & {$[4,1,3]$} & {$[0,0,0]$} & {$[4,1,3]$} & {$[0,0,0]$} \\
\hline TC [F,M,I] & {$[4,6,6]$} & {$[4,2,2]$} & {$[4,6,6]$} & {$[4,1,3]$} \\
\hline Points & 34 & 14 & 34 & 15 \\
\hline $\begin{array}{l}\text { Total } \\
\text { bonuses }\end{array}$ & 10 & 0 & 10 & 0 \\
\hline PES & 0 & 0 & 0 & 0 \\
\hline PB & 10 & 0 & 10 & 0 \\
\hline
\end{tabular}

Tokens: $\mathrm{I} \bigcirc \mathrm{M} \bigcirc \mathrm{F}$ 